\title{
Signos da diáspora na formação da identidade cultural moçambicana: a palavra poética como lugar da diferença
}

\author{
Luciana Brandão Leal*
}

\author{
Entre afro-muçulmanos e \\ Cristãos \\ Navego \\ E contra um cego \\ Império de escravos \\ E gloriosas mortes \\ Bracejo \\ (tal destro espadachim ibérico) \\ Embora meio judeu \\ Persa e azteca \\ Virgílio de Lemos, $A$ invenção das ilhas
}

A etimologia da palavra trânsito, do latim, transitus, é assim definida pelo dicionário Houaiss: "1. ato de transitar [...] 2. afluência, circulação de pessoas [...] 3. movimento de veículos em determinada área, cidade, etc.; tráfego [...]. 4.passagem, acesso [...]. 5. passagem de um lugar a outro [...]. ETIM lat. transitus, us 'ação de passar, passagem', der. do lat. transire 'passar de um lugar a outro'; passar; decorrer (o tempo)" (HouAIss, 2001, p. 2751-2752). As definições da palavra referemse a pessoas ou veículos, que se deslocam em determinado tempo e espaço, em movimento contínuo de ir e vir, o que pressupõe a interação com a paisagem e seus elementos. Os movimentos de trânsitos incorporam um complexo sistema de inter-relações. Neste artigo, consideramos alguns trânsitos literários de Virgílio de Lemos, como poeta e intelectual, assim como as diásporas que constituem suas poesias. Virgílio de Lemos recria o mundo e a paisagem que percebe por meio da linguagem, ao definirmos sua poesia como uma poesia em trânsito e, consequentemente, Lemos um "intelectual diaspórico", defendemos que o seu discurso poético advém de um lugar híbrido, resultado de uma formação arraigada nas culturas africanas e eurocêntrica, tanto no âmbito familiar quanto no que diz respeito às suas interferências culturais e literárias.

Por isso, pode-se caracterizar a sua lírica como a de um poeta sem lugar ou de todos os lugares, na mais radical acepção que se pode atribuir ao deslocamento.

\footnotetext{
Doutora em Letras e professora da Universidade Federal de Viçosa - Campus Florestal, MG,
} Brasil. E-mail: luciana_brandao@hotmail.com. 
Isso se dá porque, diante da "floresta de signos" que se manifesta em suas letras, prevalecem as memórias e as pulsões do inconsciente, que se fazem conhecer por seus efeitos. Nesse sentido, propõe-se, aqui, pensar a identidade, o pertencimento e a diferença ${ }^{1}$ que se manifestam na lírica virgiliana a partir do conceito de diáspora de Stuart Hall (2011) e Prisca Agustoni (2013). Os poemas serão analisados com base no movimento diaspórico de pessoas, ideias e signos, que não pressupõe, necessariamente, deslocamento físico.

A partir de 1940, em Moçambique, a produção poética torna-se mais autônoma, o que é prenúncio de uma literatura mais independente em relação aos parâmetros lusófonos. Nesse movimento inaugural, Virgílio de Lemos contribui com a construção de uma nova identidade para a poesia moçambicana. O poeta reinventa o lirismo adormecido sob os discursos militantes que ditavam, nesse contexto, os traços da moçambicanidade. Em sua poesia, o erotismo articula um lirismo latente, que se manifesta nos planos da linguagem e dos sentidos. Os versos evocados na epígrafe desta seção, do poema "Paisagem tropical", são sintomáticos, porque neles se constatam influências e trânsitos no espaço tropical moçambicano, com heranças étnicas e culturais afro-muçulmanas, cristãs, judias, persas e astecas. Heranças diversas que constituem o tecido e a tessitura cultural de Moçambique. Essas múltiplas feições são retomadas em versos cujos fios de sentidos e palavras são urdidos pelo eu-lírico de Virgílio de Lemos. Na seção "Vozes dissonantes" (19601963) da antologia fogos de prazer (2009), há vários poemas que abordam os trânsitos e deslocamentos que (con)formam a identidade moçambicana, como os que se patenteiam nos versos transcritos nessa epígrafe e em outros que conclamam vozes advindas de outros espaços, feições estrangeiras, afro-diaspóricas, além de vozes tutelares da cultura universal.

Em "Mortos se não formos nós", o eu lírico virgiliano estabelece, performaticamente, diálogo com a personagem da última peça de William Shakespeare, The Tempest (de 1610). Como se sabe, Caliban, é personagem dúbia e multifacetada e emblemática. Tem fascínio pela sua ilha, da qual é habitante original, e deseja matar Próspero, alegoria do colonizador. A voz poética não apenas se personifica como Caliban, mas também diz ser metonímia de outras vozes vindas das periferias e dos espaços de trânsitos "bantu-português-arabizado-indu-swahili". Tanta multiplicidade resulta em tecido cultural rasgado, esgarçado, produto de tessitura da tradição e de "ecos de vermelhos mares", que é também metáfora da violência das diásporas:

Sou Caliban e não estou só:

há poetas da cidade

e calibans da periferia

há jeitos de tradição e ecos de vermelhos mares

\footnotetext{
Stuart Hall (2011) desenvolve seus estudos sobre identidade e diferença a partir do termo différance, cunhado por Derrida. Hall oferece a ideia de rasura para explicar que as identidades se (con)formam em movimentos dinâmicos de alteridade e de pertencimento.
} 
no teu gesto cultural (rasgado)

bantu-português-arabizado

indu-swahili da Eritreia

Sena e Sofala.

És Caliban e não estás só:

a uma cultura avesso és plural

shangane que ridiculariza chope

makwa que marginaliza makonde

e português filtrado este

etno-mágico xadrez

chino-arábico-indonesino

tu interplanetário vagabundo

aventureiro Caliban dos ventos (LEMOS, 2009a, p. 409-410).

Esse poema registra e conclama heranças culturais do espaço moçambicano, mas, também, delineia a riqueza metafórica em um tabuleiro "etno-mágico xadrez", resultado da alteridade, que está no "fundo" e na "forma", uma vez que também se expressa nos primeiros versos de cada estrofe, pelas formas verbais "Eu sou" e "Tu és". Nesses verbos, veem-se o movimento, a essência e o resultado das diásporas encenadas pela "floresta de signos" de Lemos:

Sou Caliban e não estou só:

as línguas bantus subvertem

entram em tua casa sem licença,

as palavras ausentes do dicionário

são punhais que libertam o Homem. (Lemos, 2009a, p. 410).

Virgílio de Lemos se relacionou intimamente com escritores que produziram nos períodos anterior e posterior à independência dessa nação marcada por múltiplas cicatrizes do colonialismo. Moçambique, pela voz de seus poetas, persegue a unidade e a identidade (mesmo que múltipla) de uma nação em diáspora. A sua poesia é resistência, mas é, também, criação, invenção e reinvenção de um contexto insuportável de violência e falta/ausência. Lemos, como poeta e intelectual, fora profundamente ligado aos seus contemporâneos, influenciando-os diretamente, compartilhando com eles ideias e ideais. Em alguns registros, ele é considerado um escritor alheio aos dramas de seu país. Constata-se, porém, exatamente o contrário. Pela voz de Duarte Galvão, seu "heterônimo guerrilheiro" (SEcco in LeAL, 2021, p. 2), Virgílio de Lemos apresenta seus poemas de combate, poemas verticais (muitas vezes grafados em papel amarelo - o amarelo da dor, da angústia, da náusea), tais quais os de Craveirinha e Noémia de Sousa. Para além dessa faceta, ele escreveu a poesia das ilhas, da Ilha de Moçambique, do Oceano Índico, a poesia das águas verde-azul-iridescentes de um oceano que é metáfora e metonímia das hibridizações do território moçambicano. 
Quando canta a Ilha de Moçambique, por exemplo, o poeta suscita memórias desse espaço de trânsitos cuja constituição social e histórica reúne traços de culturas várias. Influências orientais e ocidentais arraigadas ao chão banto e reelaboradas por uma poética vibrante, "que busca as raízes profundas do ser africano" (SEcco, 1999, p. 17). Em Para fazer um mar (2001), a sua proposta vai além de reinventar o espaço da memória, encontro da lembrança e do sonho, intenta uma revolução pela linguagem: fazer um novo mar, o mar da poesia, o mar da linguagem erótica e da sonoridade da língua, o que é possível pela pena e sensibilidade de grande lírico. Quando evoca a sensualidade, Virgílio de Lemos o faz de forma "lúdica e trágica" (NUNES, 2009, p. XIV); o erotismo como fundo e forma da linguagem poética revela-se de maneira "profundamente desassossegada" (NunEs, 2009, p. XIV).

A tradição índica, a "indicidade", já constatada por Ana Mafalda Leite (2013) e Carmen Lúcia Tindó Secco (1999), é "metáfora do desejo, do Eros primordial a ser reencontrado" (SECCO, 1999, p. 37). Fanela para Oriente (1999) é o título de uma obra de Eduardo White e o ideal dos poetas do Índico - ideal compartilhado por Lemos, desenvolvido e reelaborado por ele. O Oriente inventado, ficcional, é também metáfora de (re)encontros e trânsitos. Ao articular seus poemas reunidos em Para fazer um mar com pinturas do moçambicano Roberto Chichorro, Virgílio de Lemos estabelece um diálogo sensorial e conceitual: da surrealidade do azul onírico à sensualidade das formas plásticas e sonoras.

O termo diáspora, cuja origem etimológica vem do grego clássico e significa, essencialmente dispersão, define o deslocamento de pessoas de uma determinada região para outra, por motivos políticos ou religiosos. Originalmente, esse termo referia-se ao povo judeu exilado na Palestina e à sua dispersão forçada a partir do exílio na Babilônia (século VI a.C.) e após a destruição de Jerusalém (em 70 d.C.). Na história moderna, o povo judeu e seu destino no Holocausto são, segundo Stuart Hall, "um dos poucos episódios histórico-mundiais comparáveis, em barbárie, com a escravidão moderna" (HALL, 2011, p. 28). A diáspora judaica fundou-se como o exílio traumático de um povo permanentemente perseguido, fazendo com que a palavra diáspora tenha uma força semântica profundamente negativa.

Deslocando-se o significado desse termo para o contexto de África, o conceito de diáspora passa a significar a migração forçada dos negros africanos para o Novo Mundo, mediada pelos países europeus colonizadores, que viram nessa empreitada a possibilidade de grande rendimento econômico - a comercialização de escravos - o que pode ser analisado pelo viés histórico, geográfico, social ou antropológico. Em suma, o violento movimento diaspórico que se configurou em territórios africanos pode ser definido como a migração forçada de pessoas para espaços de domínio europeu. Mantém-se a ideia de dispersão para se caracterizar o termo, aproximando-o da acepção judaica, já que ambas carregam a marca de movimento conflituoso e violento. Stuart Hall (2011) dedica-se às reflexões sobre a diáspora caribenha, a partir da migração da população negra afro-caribenha para 
a Grã-Bretanha, no período pós-guerra, e sobre os assentamentos negros caribenhos no Reino Unido. Em prefácio para o livro Da diáspora: identidades e mediações culturais, Lik Sovik conclui: "o pensamento de Hall passa por convicções democráticas e pela aguçada observação da cena cultural contemporânea”, (SovıK, 2011, p.11). Dada a relevância desse estudo e a possibilidade de, a partir dele, pensarmos a complexidade das identidades em construção, ele pode ser aplicado a outros espaços, como é o caso de Moçambique. Segundo o teórico jamaicano, o conceito de diáspora não deve ser pensado apenas pela conformação binária das diferenças, já que tais definições não abarcam a identidade cultural dos povos em diáspora. A identidade é "uma costura de posição e contexto" (SoviK, 2011, p. 15) e não um conceito aleatório a ser estudado com base na fronteira da exclusão. Stuart Hall (2011) usa a expressão "zona de contato" para definir a construção identitária de sujeitos, antes separados geograficamente, cujas trajetórias se encontram:

As configurações sincretizadas da identidade cultural caribenha requerem a noção derridiana de différance - uma diferença que não funciona através de binarismos, fronteiras veladas que não separam finalmente, mas são também places de passage, e significados que são posicionais e relacionais, sempre em deslize ao longo de um espectro sem começo e nem fim (HALL, 2011, p. 33).

Ao trazer para discussão o conceito derridiano de différance, Stuart Hall (2011) possibilita melhor compreensão da busca pela diferença que Virgílio de Lemos expressa em seus poemas. Essa acepção está encenada no poema "Procura-se: a diferença", no qual Virgílio de Lemos, desde o título, assume o compromisso de hibridizar a sua linguagem poética, bem como as letras moçambicanas.

Procura-se: a diferença

eu vivo

produto da literatura

codifico a linguagem

da diferença

(pelo menos étnica

e cultural

pelo menos

aqui)

concretista desordeiro

ávido

de vertigem

sou o exílio

minha esperança ficará

exaltante de demagogia

nas entrelinhas

da metafísica e 


\author{
da linguagem... \\ real sem profeta \\ colorido \\ em cada palavra reescrita \\ e reinventada \\ nascida morta ressuscitada \\ procura \\ minha excessiva utopia \\ constelação diagrama \\ no teu céu astral \\ desmemoriado \\ nego ser cúmplice \\ não serei "sem vergonha" \\ fora da máquina infernal \\ codificarei outra linguagem \\ da diferença \\ eu vivo \\ produto da literatura. (LEmos, 2009, p. 384-385, grifo nosso)
}

Aí se vê o "jogo da semelhança e da diferença" (HALl, 2011, p. 45). O texto é escrito em língua portuguesa, idioma imposto pela colonização, mas o enunciado propõe justamente o contrário: a busca de expressão étnica e cultural, a desordem no código dito padrão da linguagem: "Concretista desordeiro / ávido / de vertigem / sou o exílio" (Lemos, 2009a, p. 384). O compromisso que se estabelece é o de reinventar as palavras e, na vertigem do texto literário, reescrevê-las e ressuscitálas, a fim de "codificar outra linguagem / da diferença" (LEMOS, 2009a, p. 385), que é produto vivo da literatura.

O poema lido encena os movimentos fundadores do conceito de diáspora. Stuart Hall (2011) aponta para a questão do hibridismo e da reconfiguração cultural que resulta desse processo, uma vez que, em situação de diáspora, as identidades tornam-se múltiplas. Seu pensamento capta a tensão existente no hibridismo cultural e na mestiçagem que advêm de diversos níveis da formação social: político, econômico e cultural. A identidade resultante do movimento diaspórico, como é o caso de Moçambique, espaço de vários trânsitos culturais e identitários, fundase a partir de encontros que a tornam irremediavelmente "impura", já que tem o seu centro cultural em todo lugar e em lugar algum, tornando-a descentrada. Sob essa perspectiva, as imbricações culturais advindas desses percursos resultam na subversão de modelos tradicionais; torna-se "desterritorializante" em seus efeitos.

Prisca Agustoni (2013) ampara-se na teoria de Stuart Hall (2011) e de outros pensadores contemporâneos para analisar os signos da diáspora africana na poesia escrita em língua portuguesa, a propósito de textos de autores africanos (Luís Carlos Patraquim, Paula Tavares e Ruy Duarte de Carvalho) e brasileiros (Ricardo Aleixo, Ronald Augusto e Edimilson de Almeida Pereira). Para ela, a dispersão pode ser 
encontrada em expressões artísticas e culturais, configurando-se a partir dos signos e significados.

Neste sentido, o espaço passa a ser considerado como um circuito comunicativo, um solo fértil e compartilhado por todos aqueles que neles fazem transitar os signos, mais além dos absolutismos ou anelos de purezas étnicas. Da mesma forma, a folha de papel torna-se para o poeta um instrumento a serviço não só da memória, mas também do desejo de ruptura, no qual é possível gravar novos códigos, novos deslocamentos, não necessariamente relacionados com o universo simbólico do escravo (Agustoni, 2013, p. 17).

A plurivalência social dos signos decorre da sua natureza, "desarticulando certos signos e rearticulando de outra forma seu significado simbólico. A força subversiva dessa tendência hibridizante fica mais aparente no nível da própria linguagem" (Mercer, apud HALL, 2011, p. 33). Essas expressões culturais surgem em espaços cujos povos se encontram em situação diaspórica, o que os fazem assimilar tanto a herança cultural nacional quanto experiências advindas de outros povos e lugares. No caso da poesia moçambicana, constata-se, muitas vezes, a rasura e a carnavalização da língua portuguesa; nos textos desses escritores, as várias línguas africanas criam movimentos performativos (quase teatrais) na dimensão dos signos, rearticulando também os campos semânticos, sintáticos e lexicais.

Reiteradas vezes, Virgílio de Lemos resgata a metáfora das "raízes aéreas", conceito que é fundamental para a compreensão da lírica de um poeta em trânsito. Lemos diz das "raízes aéreas" ligadas ao Oceano Índico - conceito que Ana Mafalda Leite (2013) retoma como "raízes índicas". No poema "Estalo da língua" (LEMOS, 1999b, p. 132), essas mesmas raízes aéreas são metáfora e metonímia do alcance da linguagem, dos hibridismos, das diásporas. Novamente, em "Msaho Dada", as raízes aéreas se espalham em ramificações de múltiplas conexões culturais, alcançando influências diversas, das culturas moçambicana, ocidental e universal:

Moçambicanis

msaho

de raízes aéreas

de ilha em ilha

mar

descentralizado DADA (Lemos, 1999a, p. 30-31).

A imagem dessas "raízes aéreas" vai ao encontro do pensamento de Glissant, quando explica a noção de relação e explicita a ideia de movimento, a confluência de culturas, a proposta de uma "identidade relação" articulada a partir de uma raizrizoma, que se conecta a outras raízes, forma que "irradia" e "dispersa". O mesmo impulso que está implícito na noção de relação determina outros impulsos culturais, deslocando-os e transformando-os. De fato, as "raízes aéreas" - imagem reiterada poeticamente - tornam-se bastante significativas na lírica virgiliana por- 
que resgatam, metaforicamente, os trânsitos desse escritor moçambicano. As "raízes aéreas" dizem respeito à focalização que motivou este trabalho de pesquisa: os vários trânsitos de Virgílio de Lemos - como homem, intelectual e, sobretudo, poeta. Multiplicando as ideias de deslocamento, Virgílio de Lemos recorre às metáforas da "ave migratória" e do "pássaro migrante", que se fazem como um manifesto conceitual e identitário:

Ave sempre migratória, sempre

de passagem

entre coisas,

matérias, cores e

transparências, sons

que aparecem para logo sumir (Lemos, 2009, p. 131).

Importa perceber que o caráter diaspórico presente nas manifestações culturais de territórios massacrados pelo colonialismo, no caso de Moçambique, configurase como uma forma de subversão aos modelos culturais impostos aos espaços colonizados. A partir do processo de sincretização de influências e signos, são produzidas as identidades moçambicanas; "só que, agora, operam dentro de uma referência diferente de tempo e espaço, um cronotopo distinto - no tempo da différance" (HALL, 2011, p. 33). Ao incorporar à sua escrita as referências ao jazz e ao blues norte-americano, Virgílio de Lemos assume novamente a postura diaspórica e traz ao espaço enunciativo as vozes marginalizadas de artistas negros, transportando, sincreticamente, a música e o ritmo desses lugares para alguns de seus poemas. A sua proposta é a de recuperar fontes e influências de vozes negras para reafirmar a sua opção pela arte e pela cultura emergentes da periferia. No poema "Um blues is born", por exemplo, tem-se:

Um blues is born

In the fire on fire in fire

FIRE...

(instante fugaz)

Um blues is born

Nasceu um blues

(lâmina de cobre)

Um puzzle uma estrela

Voz submersa

Adolescente

Que vem d'alma

Billy Holiday

De pés descalços

Desolada chora 
O evangelho emudeceu

In the fire on fire in fire

FIRE...

Sem escrúpulos a justiça

Contra a fome

E a esperança! (Lemos, 2009a, p. 137).

O texto transcrito está eivado, ou contaminado por registros múltiplos, o que determina o percurso de decodificação dos sentidos. Tem-se aí a riqueza polifônica dada pela utilização de palavras em língua inglesa em um discurso em língua portuguesa, carnavalizando-o. A poesia é atravessada por outras vozes, trazendo-lhe os sons e o ritmo do blues americano. A rasura do código linguístico ganha múltiplas especificidades, "não apenas a voz, mas também a mímica, a gestualidade e a ritualidade" (AgUSTONI, 2013, p. 23).

A palavra "FIRE", grafada em letras maiúsculas, é um exemplo da gestualidade e da ritualidade sobre as quais escreve Prisca Agustoni. O signo se desdobra em múltiplas significações, permitindo interpretações que vão desde a intensidade e a fugacidade do elemento "fogo" (que também estão na música e na poesia) até os sentidos de resistência política que o poema pretende encenar. Uma resistência que apela ao grito que o Evangelho emudecera. A referência ao Evangelho pode indicar o deslocamento operado pelo blues a partir dos spirituals, movimento pretendido pelo poema quando sugere o nascimento de um blues que é esperança contra a fome. O sentido político-social afasta-se do sentido religioso em "grito daqueles que não gritam" (Augustoni, 2013, p. 23).

Sons provenientes das ruas e dos guetos, "vozes submersas" estão metonimizadas pela referência a Billy Holiday. A palavra encenada está enraizada no contexto cultural moçambicano, mas resgata elementos de espaços configurados pelo gênero musical blues. É um novo blues que nasce, um blues moçambicano, plural, como plurais são os registros estéticos diaspóricos. Em texto emblemático, conclamando as vanguardas para instituir, com elas, a novidade no cenário colonial, Virgílio de Lemos subverte, mais uma vez, a língua portuguesa e seus próprios conceitos. Em "For Black's Only", a voz lírica cria novo conceito de "colonofagia", produto antropofágico da diferença que é aqui apresentada e discutida:

\author{
FOR BLACK'S ONLY \\ c olo n of a g i a \\ das cinco em Setembro feiticeiro \\ do xipamanine \\ com licença comercial \\ happening permanente \\ concretista \\ dadaísta \\ não menos radical (LEMOS, 2009a, p. 386).
}


Retomando-se o pensamento de Prisca Agustoni: "a palavra se converte em discurso simbólico, grito daqueles que não gritam, registro histórico e poético de uma cultura pressionada pelo seu olhar e pelo olhar exterior da história" (AgUsTONI, 2013, p. 53). Ainda segundo essa pesquisadora, quando se remete ao blues, nesse contexto, reafirma-se um campo dialógico, "tecendo uma rede de conexões com o universo diaspórico do Atlântico negro, do qual o blues é uma das manifestações mais conhecidas" (Agustoni, 2013, p. 72). Temos, aí, um exemplo de produção cultural híbrida, diaspórica, na medida em que incorpora o discurso do outro, reiterando-o e transformando-o. Virgílio de Lemos comprova, mais uma vez, seu olhar aberto para o outro, para o mundo.

\section{Referências}

Agustoni, Prisca. O Atlântico em movimento: signos da diáspora africana na poesia contemporânea de língua portuguesa. Belo Horizonte: Mazza Edições, 2013.

Dicionário Houaiss da Língua Portuguesa. Rio de Janeiro: Objetiva, 2001.

Hall, Stuart. Da diáspora: identidades e mediações culturais. Organização Liv Sovk. Tradução de Adelaine La Guardia Resende et al.. Belo Horizonte: Ed. UFMG, 2011.

LEAL, Luciana Brandão. Descolonizar a palavra: poesia moçambicana do século $\mathrm{XX}, 2 \mathrm{O} 21$ (No prelo).

Leite, Ana Mafalda. Literaturas Africanas e Formulações Pós-Coloniais. Lisboa: Edições Colibri, 2013.

Lemos, Virgílio de. Ilha de Moçambique - a ilha é o exílio do que sonhas. Maputo: Amolp, 1999b.

Lemos, Virgílio. A invenção das ilhas. Organização e posfácio de António Cabrita. Maputo: Escola Portuguesa de Moçambique, 2009.

Lemos, Virgílio de. Negra Azul: retratos antigos de Lourenço Marques de um poeta barroco (1944-1963). Maputo: Instituto Camões - Centro Cultural Português, 1999.

Lemos, Virgílio de. Para fazer um mar. Lisboa: Instituto Camões, 2001. (Coleção Insularidades).

Lemos, Virgílio de. Jogos de prazer. Virgílio de Lemos \& heterónimos: Bruno Reis, Duarte Galvão e Lee-Li Yang. Organização do volume e prefácio de Ana Mafalda Leite. Lisboa: Imprensa Nacional - Casa da Moeda, 2009.

SeCCo, Carmen Lúcia Tindó. Antologia do mar na poesia africana de língua portuguesa. Rio de Janeiro: Faculdade de Letras da UFRJ, 1999.

Secco, Carmen Lucia Tindó. Prefácio. Leal, Luciana Brandão. Descolonizar a palavra: poesia moçambicana do século XX. [2021]. 132 p. (No prelo). 
Sovik, Liv. Apresentação: para ler Stuart Hall. In: HALL, Stuart. Da diáspora: identidades e mediações culturais. Organização Liv Sovik. Tradução de Adelaine La Guardia Resende et al.. Belo Horizonte: Ed. UFMG, 2011. p. 9-21.

Recebido em 18 de março de 2021.

Aprovado em 28 de junho de 2021.

\section{Resumo}

Signos da diáspora na formação da identidade cultural moçambicana: a palavra poética como lugar da diferença

\section{Luciana Brandão Leal}

Neste artigo, apresenta-se uma leitura dos poemas de Virgílio de Lemos com o objetivo de analisar os percursos diaspóricos propostos por esse escritor em diversos momentos de sua obra, para então situá-lo no cenário da moderna poesia moçambicana. Tais reflexões amparam-se no conceito de diáspora proposto por Stuart Hall (2011) e retomado por Prisca Agustoni (2013) que consideram os movimentos diaspóricos de pessoas, ideias e signos, não se limitando ao deslocamento físico.

Palavras-chave: Virgílio de Lemos, diáspora, identidade, poesia, culturas, trânsitos. 